\title{
TRANSIÇÕES DOS ESTÁDIOS DA VIDA EM KIERKEGAARD E SUAS PERSPECTIVAS TEOLÓGICAS
}

\author{
Kierkegaard's stadiums of life transitions and its \\ theological perspectives
}

Transiciones de las etapas de la vida en Kierkegaard y sus perspectivas teológicas

Lauro Ericksen

\section{Resumo}

Aborda os três estádios (estágios) da vida humana tal como propostos por Kierkegaard. Foca na possibilidade de transição entre os estágios e as aplicabilidades teológicas de cada posicionamento descrito. Analisa o caráter existencial e antissistemático do pensamento kierkegaardiano; considera esses aspectos como relevantes em uma defesa do cristianismo ante à filosofia (hegeliana). Argumenta que o estádio religioso é o ápice da existência humana provisionado pelo salto de fé, ainda que conectado com os demais estádios existenciais, independentemente de qual estágio um homem se encontre. A transição e variação entre os estádios são tomadas como um resultado da existência: é algo possível e comum ao homem, não sendo impossibilitadas segundo o atual estágio de vivência. Não incapacitam a simultânea e mútua intersecção entre

1 Doutor, mestre e bacharel em Filosofia pela Universidade Federal do Rio Grande do Norte (UFRN). Oficial de Justiça Avaliador Federal no Tribunal Regional do Trabalho do Rio Grande do Norte $-21^{1}$ Região (TRT-21). Especialista em Direito e Processo do Trabalho (Universidade Cândido Mendes - UCAM/ RJ). Bacharel em Direito (UFRN). Dados disponíveis em: http://lattes.cnpq.br/8447713849678899. http://orcid.org/0000-0002-4195-1799. E-mail: lauroericksen@yahoo.com.br. 
os estádios, algo factível segundo a perspectiva teológica kierkegaardiana. Conclui que o estágio religioso é o desígnio existencial (e teológico) máximo após o salto de fé. Palavras-chave: Filosofia. Existencialismo. Teologia. Cristianismo. Estádios da vida.

\begin{abstract}
The paper discusses the three stadiums (stages) of life proposed by Kierkegaard. It focuses on the possible transition of stages and its theological appliances. The work analyzes the anti-systematic and existential position of Kierkegaard; it considers these aspects as a standing point of Christian defense against philosophy (Hegelianism). It argues that the religious stadium as a high evaluated stage of human existence, even though it can be connect to others stadiums as well. The possibility of transition and variation among stages is taken as a result of human life: possible and ordinary. It does not forbid the mutual and simultaneous intersection of stages, thus, providing a vast scenario of possibilities. It concludes stating the religious highness as a theological preference after the leap of Faith.
\end{abstract}

Keywords: Philosophy. Existentialism. Theology. Christianity. Life Stadiums.

\title{
Resumen
}

Analiza las tres etapas (etapas) de la vida humana, tal como propuesto por Kierkegaard. Se centra en la posibilidad de transición entre las etapas y las aplicaciones teológicas de cada posición descrita. Analiza el carácter existencial y antissistemático del pensamiento kierkegaardiano y considera estos aspectos como relevantes en una defensa del cristianismo frente a la filosofía (hegeliana). Sostiene que el estadio religioso es el ápice de la existencia humana, provisionada por el salto de fe, aunque conectado con los otros estadios existenciales, sin importar qué etapa el hombre se ubica hombre en su momento actual. La transición y la variación entre los estadios son tomadas como resultado de la existencia: es posible y común al hombre, no siendo impedido conforme a la actual etapa de su vida. No excluye la intersección mutua y simultánea entre los estadios, algo factible segundo la perspectiva teologíca kierkegaardiana. Concluye que el estagio religioso es el designio existencial (y teológico) máximo tras el salto de fe. Palabras clave: Filosofía. Existencialismo. Teología. Cristianismo. Etapas de la vida. 


\section{Introdução}

De acordo com sua compreensão da realidade, Søren Kierkegaard aponta a existência humana repartida em três estádios: o estético, o ético e o religioso. Há uma gradação em termos de aprofundamento (subjetivo) entre os três estádios descritos pelo filósofo. A partir dessa compreensão, há a antecipação que se chegará em Kierkegaard na defesa do cristianismo: o estádio religioso é o ápice da vida humana.

O estádio religioso é posto como a compreensão mais profunda de si mesmo, de Deus e de Cristo. Ele é sinônimo de aprofundamento cristão, de compreensão de Deus, do modelo de Cristo vivido em sua plenitude e em sua perfeição. Não há operação de defesa, em prol do cristianismo, mais fervorosa que a empreendida por Kierkegaard; para ele, não há vida autêntica possível sem Cristo, sem Deus e sem a noção teológica de cristianismo por ele defendida.

Assim sendo, ainda que o resultado de mais profundidade e de alta relevância seja conferido ao estádio religioso (ou o estádio da vida religiosa), há de se ter em conta que no espectro mais elementar a vida humana pode ser definida de acordo com o interesse e o seu contraponto, o não interesse. Determinar o que é interessante e o que não é interessante se estabelece a partir da definição, de maneira bastante simplória, de estádio estético. Ainda que seja compreendido como o estágio mais elementar da vida do homem, em sua complexidade mais comezinha e ingênua, Kierkegaard se vale de tal estádio de modo extremamente abrangente, pois definir a atuação do homem de acordo com seu interesse ou desinteresse abarca uma miríade de possibilidades, das mais variadas possíveis.

A filosofia, ou a busca do homem pela filosofia, colocando-a como algo interessante ou desinteressante, reside, portanto, no estádio estético da vida humana. Além da filosofia, qualquer outra atividade ou outro pensamento que denote interesse ou desinteresse por parte daquele que age ou pensa, igualmente estará equiparada ao elemento estético prevalente em tal empreitada. Desse modo, a vida de qualquer estudioso ou cientista 
também será julgada por Kierkegaard segundo critérios estéticos. No entanto, há de se salientar, não apenas escolhas ou possibilidades nobres se enquadram no critério estético, haja vista que atividades simplórias e corriqueiras também se encontram inseridas na perspectiva estética, como, por exemplo, as atividades econômicas, culturais e esportivas, para se citar apenas uma pequena parcela do leque de possibilidades enquadrado por esse estádio em específico.

De maneira a favorecer uma abordagem didática do presente artigo, é de grande valia traçar um esboço de sua apresentação por seção. Ele se dividirá, além dessa breve introdução, em mais duas seções de desenvolvimento, sendo que a terceira seção se subdividirá em duas, contando com breves considerações finais posteriores a essas duas seções.

Assim, a próxima seção deste artigo tratará do estádio estético em Kierkegaard, e irá fornecer uma breve conceituação ao explorar a variabilidade de interesses do homem como fundamento existencial para a construção desse estádio.

A segunda seção se dedica a uma abordagem das formas de transição entre os três estádios da vida humana em Kierkegaard: do estético para o ético, do ético para o religioso e do estético para o religioso. Inicialmente, para que seja possível discutir as possibilidades de transição entre os estádios, será feita uma breve conceituação de cada um. Assim, haverá uma busca, mais uma vez, sobre o interesse no estádio estético, como também a normatividade no estádio ético e o aprofundamento subjetivo e intimista do homem com Deus no estádio religioso. Ademais, será debatida a possibilidade de operacionalidade em conjunto entre os estádios, principalmente entre as voltas existenciais no estádio ético e estético, em concomitância. Essa seção será subdividida em duas subseções.

A primeira das subseções tem como objetivo fazer uma pormenorização da coletividade normativa e o estádio ético da vida humana; irá, também, resgatar os fundamentos kantianos da abordagem de Kierkegaard ao demonstrar mais estabilidade desse estádio quando comparado ao estádio estético. A outra subseção se dedica à abordagem do estádio 
religioso, e dá ênfase ao momento crucial de transição denominado de salto de fé. Essa subseção analisa o salto de fé do ponto de vista qualitativo; demonstra, assim, como ele vislumbra as possibilidades de aprofundamento subjetivo com Deus ao dar mais solidez à noção de verdade subjetivamente construída no estádio religioso.

\section{Critérios de Interesse no Estádio Estético de Kierkegaard}

Para melhor compreender os estádios da vida humana, é necessário tratar da conceituação, ainda que mínima, do estádio estético, e também apresentar como a categoria do interesse guia esse estádio e forma a sua compreensão. Há uma série de atividades e comportamentos humanos que se enquadram no estádio estético; tudo que possa ser gerido pela dialética do interesse e do desinteresse encontra-se dentro do estádio estético. Por causa dessa grande amplitude, entende-se que o estádio estético é o que abrange o maior número de possibilidades de desempenho na vida do homem, não sendo possível sequer descrever todas as atividades que podem ser inseridas no conjunto estético de atuação.

De maneira bastante simples, exposta pelo próprio Kierkegaard (1955, p. 35), "a estética em um homem é aquilo pelo qual esse homem é, imediatamente, o que ele é, ele que vive na estética, pela estética, da estética e para a estética que há em si mesmo, vive esteticamente". Dito de outra forma, a estética é aquilo que engloba o conjunto de atividades e de ações de interesse do homem, aquilo que ele é de maneira mais imediata, mais clara e mais sensível do ponto de vista mais aparente possível em sua vida cotidiana. A estética, portanto, é esse conglomerado de enunciados da vida comum que fazem do homem aquilo que ele é, da maneira mais imediata, repisa o próprio Kierkegaard (1955, p. 32), pois a estética é aquilo do que se vive para o que se vive. A estética é o que provoca o interesse e o que é capaz de manter o interesse, e, derradeiramente, aquilo também para o qual esse mesmo interesse se direciona, 
segundo as premissas mais elementares daquilo que o homem é, em seu imediatismo de interesses e de buscas triviais.

O interesse mais primário e mais simples é o que guia o critério estético desse mencionado estádio da vida humana. A consecução de tal interesse é o fim último de tal perspectiva cotidiana da vida de cada homem. As escolhas de cada um, sejam elas quais forem, segundo o seu interesse, são tão factíveis e aceitáveis quanto elas forem passíveis de realização; não há um critério válido nas escolhas. Kierkegaard (1955, p. 40) menciona que as escolhas no estádio estético não têm critérios. No estádio estético há arbitrariedade na escolha pela escolha, sem que nenhum critério sirva de razão no ato de decidir (PIERCEY, 2009, p. 91). Semelhantemente, as escoIhas não se constituem a partir de um caráter moral, elas não são boas ou más por si mesmas, elas não são teologicamente guiadas (sob pena de se ferir o livre-arbítrio humano), poia a liberdade de escolha é o fundamento para a própria escolha e por isso sua motivação se mantém inexplicável (KNAPPE, 2004, p. 96). Esse ponto é importante para designar a abrupta separação entre o estádio estético e os demais estádios contemplados na vida humana. A razão disso é que não há nenhuma distinção ética ou religiosa que se aprofunde ou se estenda ao nível de interesse de cada um em perseguir qualquer meta que seja, não há julgamento nos interesses, não há nada que se suplante dentro da ótica mais elementar da escolha.

Nessa esteira, há de se dizer que o esteta tem ojeriza ao que se pode tornar solidificado na realidade, por isso sua busca por interesses diversos para evitar o tédio é o que centra sua busca no absoluto. Plantar a direção do seu prazer em uma coisa apenas, ou seja, centrar seu interesse, significa abdicar das demais possibilidades de escolha, algo que ele não quer, pois, a indefinição de todos os interesses possíveis o atrai mais que um interesse em específico. Ele evita encarnar-se no que é finito, e, assim, obter uma efetivação da realidade a ele dada por suas próprias escolhas (FARAGO, 2006, p. 89). O instante é o ponto de aperfeiçoamento do esteta, em oposição dialética à eternidade (encontrada no estádio religioso, por exemplo). O problema é que o esteta não compreende que a cada escolha tem-se, por consequência, 
uma renúncia (MIDDLETON, 2003, p. 9). Por não compreender a noção de tempo (ou melhor, por não compreender a efetivação da realidade no finito de cada escolha), o esteta tem a percepção que todas as escolhas são válidas concomitantemente, e busca todas elas de modo irrefreável pelo prazer do ato de escolher, sem estar atento às consequências das renúncias pelas escolhas que não são feitas quando alguma escolha é feita.

Na dinâmica da temporalidade kierkegaardiana há uma inserção recíproca entre o tempo e a eternidade. $O$ tempo é a constante interrupção da eternidade, ao passo que a eternidade penetra o tempo em contraposição (dialeticamente falando). Dessa configuração de temporalidade, o ponto de junção entre o tempo e a eternidade ocorre quando o homem deve optar entre o finito e o infinito, a oposição dialética da temporalidade, sempre presente. Fincar a escolha na realidade temporal é uma necessidade do homem se decidir, pois decidir implica escolher algo em detrimento de outra(s) possibilidade(s) qualquer(quaisquer), excluindo-a(s). No entanto, o esteta almeja procrastinar esse momento sem "presentificá-lo", sem torná-lo efetivo no presente. É no "momento" em que o tempo e a eternidade se encontram que a verdade eterna vem à lume para o homem em sua existência temporal (NYGREN, 1981, p. 107). Ele recusa o efetivo (do presente) para se embrenhar nas margens das possibilidades de seus próprios interesses.

A diversificação dos interesses sempre multifacetados e cada vez mais complexos e alterados em relação às escolhas anteriores é o objeto último de desejo do esteta. O esteta tem uma insaciável necessidade pela variedade (BERGMAN, 1991, p. 53), e essa assertiva resume bem a sua sanha pelo novo e pelo que lhe é (in)variavelmente desconhecido. A recusa do efetivo momento de uma única escolha (concentração do interesse) é o que possibilita ao esteta continuar tendo múltiplas e (quase) infinitas possibilidades de ser aquilo que ele imagina sempre poder vir a ser.

O esteta se vê imerso no absoluto, pois considera que as suas possibilidades, baseadas em seus interesses mais próprios, são sempre o horizonte de infinidade que o absoluto pode lhe prover. A paixão do esteta pelo 
absoluto poder de antever novas possibilidades esconde seu maior medo, sua maior fraqueza, que é o tédio de viver. O tédio desdenha dos remédios do espírito, busca incessantemente novas formas exóticas de distração e afunda na decadência, tornando-se devocional a procura de novos interesses (PODMORE, 2011, p. 55). Fugir do tédio é uma forma de abastecer a busca que o esteta possui por novos interesses, de modo incessante e cada vez mais amplo, por novos preenchimentos de seu vazio existencial.

$O$ vazio existencial é verificado no tédio em virtude de ele ser um locus fenomenológico em que se considera haver uma "despossessão subjetiva de si-mesmo" (KANGAS, 2007, p. 62). No tédio, o sujeito perde a posse de sua própria subjetividade, há uma negação de si-mesmo nesse instante, para que os interesses possam se tornar absolutos nas possibilidades existentes. O sujeito abdica de si para que possa sempre experimentar novas formas de possibilidade, soltas no mar de efemeridade que ele julga ser absoluto.

Por meio do tédio o sujeito é desconectado da posição de estar apto a se centrar em si mesmo, subjetivamente. Assim, o homem se encontra expelido em um processo no qual não pode se ordenar de acordo com os inícios e os fins que ele mesmo se impõe, ele não é capaz de se projetar existencialmente. Ele encontra a si mesmo posto no tempo como vazio, o mero transcorrer de novas possibilidades não lhe traz nada de concreto ou autêntico.

Fugir do tédio em busca do absoluto de possibilidades, ou perder-se na falta de subjetividade que o tédio oferece são duas opções pouco atrativas existencialmente (ERIKSEN, 2000, p. 27). De um lado, perde-se o norte mais autêntico da subjetividade, em se ter um projeto de vida sólido e enquadrado em possibilidades concretas, que não representem somente partes momentâneas. Por outro lado, afunda-se na falta de subjetividade, no pleno vazio existencial de não se decidir, a habitualidade de se escapar para o prazer sensual desconectado em si mesmo (McDONALD, 2009, p. 65). É o ponto mais profundo que se pode chegar da dispersão subjetiva no marasmo contínuo de não ter a posse de si mesmo. O tédio domina aquilo que não se pode decidir concretamente. 
Assim, do mesmo modo que se conter no tédio é uma opção existencialmente pobre ao homem, se lançar indefinidamente no absoluto de possibilidades e de novos interesses é como se lançar em mar aberto sem nenhuma forma de se salvaguardar; ambas têm implicações danosas à vida do homem.

No entanto, há de se denotar que não se deve operar uma crucificação do estádio estético em Kierkegaard, como se ele fosse raiz de todo o mal da humanidade. Afinal, em última instância, o processo pela busca de novos interesses é o motor do desenvolvimento científico da humanidade, por exemplo, para se citar algumas das benesses do estádio estético. Ele serve como fio condutor da diversidade e da multiplicidade humana, é o que motiva o homem a inovar e a transformar a natureza e a si mesmo, de modo constante e contínuo. Sem o estádio estético haveria apenas a repetição de interesses e a "mecanização" do mundo, como se ele fosse padronizado em suas formas e em suas manifestações humanas.

Ademais, deve-se ter em conta que o estádio estético, na maioria dos casos, não some quando há a transição para o estádio ético por exemplo. A questão da permanência de elementos estéticos será discutida apropriadamente mais adiante, e neste ponto serve como indicativo de que a prevalência do estádio estético é concomitante com outros estádios (ao menos com o ético essa assertiva é plena). Assim, o interesse do homem por coisas ou atividades não some ou desaparece simplesmente, como se ele deixasse de antever o absoluto em tais possibilidades. É possível que o homem centre seus interesses e os mantenha acondicionados de modo adequado, mesmo quando ele se guia a agir de acordo com os ditames do estádio ético, por exemplo. O estádio estético, portanto, não deve ser crucificado ou aniquilado como nocivo e danoso por si próprio ao ser humano.

\section{Transições e alternâncias entre os estádios da vida: do estético ao ético e a inserção subjetiva do estádio religioso}

Além do estádio estético, há outras possibilidades teológico-existenciais para o homem, outros estádios que Kierkegaard aponta como 
essenciais na formação da humanidade. A seção a seguir tratará dos dois outros estádios da vida humana que ainda não foram abordados: o ético e o religioso. Para tanto será dado um breve enquadramento do estádio estético em sua correlação com os demais estádios, fazendo a relação de uma prevalência contínua entre dois ou mais estádios, de acordo com suas possibilidades. Ademais, serão apresentadas, com o aprofundamento devido, a conceituação do estádio ético e suas disposições normativas de como o homem se comporta coletivamente; ainda, há a apresentação do estádio religioso e o complexo entendimento subjetivo entre o homem e Deus, com o intuito de discorrer sobre a construção da verdade.

No estádio estético, dada a própria gama ampla e quase infindável de possibilidades já levantadas anteriormente, o indivíduo em sua singularidade deixa-se levar por momentos e circunstâncias aleatórias de sua vida (ALMEIDA; VALLS, 2007, p. 34). Assim, ele não se afigura capaz de ter uma determinação existencial de modo a se projetar radicalmente, com compromisso e determinação responsável por aquilo que meramente se interessa. Ele não possui, ainda nesse estádio, um projeto de vida estável e predefinido. Não há um norteamento existencial que o direcione ou que condicione suas ações e seus comportamentos. O esteta se guia pelo prazer gerado pelos interesses, sem se importar, atentamente, com as consequências de seus prazeres, daí o indivíduo "deixar-se levar" pelas contingências da vida.

A vida, no traçado do estádio estético, transcorre segundo critérios de efemeridade e acidentalidade, e não há nada de perene em tais determinações, por mais que elas sejam existencialmente relevantes não se solidificam no destino de cada homem. Desse modo, o indivíduo singular é apenas um inebriado prisioneiro de vários meios que se tornam disponíveis a ele, sejam tais meios financeiros, físicos ou próprios da juventude de cada um. Então, não se perpetuam com outros critérios de maior relevância para outros estádios, como a noção de responsabilidade e continuidade.

A noção de fugacidade do estético para Kierkegaard (1955, p. 82) é, em grande parte, mais uma crítica ao sistema hegeliano. O ponto mais incisivo na contraposição de Kierkegaard a Hegel (1977, p. 144) é a questão de sua 
sistematicidade filosófica, e tal ponto remanesce mais uma vez colocado como uma crítica ao sistema hegeliano a partir do esteticismo kierkegaardiano (LIEHU, 1990, p. 72). A partir da "absolutização" do momento-imediato do esteta, há uma incorporação do absoluto em termos de imanência, do mesmo modo que o indivíduo (em seus interesses) se encontra divinizado; e na mesma medida em que o Absoluto é reduzido à mera aleatoriedade contida no acidente, e em sua efemeridade momentânea.

Na premissa estética básica que o momento é tudo, o Absoluto de Hegel (1977, p. 149) perde sua força sistemática, ele não opera mais de modo prevalente, e sua suposição é meramente teórica e incipiente para os fins de totalidade sobre os quais ele se dedicava desde sua concepção conceitual. A escolha em forma de "eleição absoluta de si mesmo" chega ao limite do desespero (RUDD, 1997, p. 79). Nessa seara, há de se entender que o "desespero" (Sygdom, termo utilizado no original dinamarquês) é um conceito bastante peculiar no conjunto da obra de Kierkegaard, sendo tratado em passagens diversas, nomeando até mesmo uma de suas obras principais, $O$ desespero humano. No presente tratamento dos estádios da vida humana, o desespero assume o ponto máximo da queda do homem, no sentido escatológico de queda e redenção que pode ser dado à vida humana por meio dos três estádios por ele pensados. Esse é o limite máximo entre o estético e o ético, uma linha que distingue os dois estádios sem os colocar de modo operante em confrontação mortal, mas que dá possibilidade à crítica ao hegelianismo. $O$ mencionado limite prepara o pensamento de Kierkegaard (1980, p. 48), como um todo, a alçar novos entendimentos rumo a um projeto de vida mais robusto no estádio ético. O desespero opera certo torpor na alma do homem, tal como se ele estivesse adormecido, necessitando de um caminho que o direcione ao outro estádio, o estádio ético.

O esteta não ama nada, não ama nem a si mesmo, cada momento em apartado do tempo é tido e absorvido por ele tal qual o absoluto, e a aleatoriedade de momentos absolutizados faz com que ele se perca em seus próprios interesses, não sendo, assim, nem mesmo capaz de amar 
a si mesmo. Cada totalidade (parcial de momentos) é eternizada pelo esteta. Dada a imediatidade de cada eternidade por ele construída (ou compreendida, por assim dizer) há apenas a busca do prazer imediato (muito embora, Kierkegaard, em nenhum momento se valha do termo "hedonista" para caracterizar o esteta).

Há uma total incompletude de satisfação de interesses, uma vez que eles são amplos e diversos, quase infinitos. Por causa dessa variabilidade quase incomensurável de interesses, agrada mais ao apetite do esteta o leque de possibilidades do que a própria realização de cada interesse ou de cada prazer (GOUVÊA, 2000, p. 211). Por causa dessa busca incessante, o esteta não se afigura capaz de formar um ideal de vida, um propósito, um verdadeiro projeto que sirva de guia e que perdure mais do que um simples momento de sua vida. A efemeridade é o motor dessas múltiplas possibilidades de prazer e de buscas, a possibilidade é a forma mais adequada da busca, uma vez que ela não fecha em si mesma nenhum ciclo ou nenhuma responsabilidade que perdure mais do que o próprio momento tomado por absoluto, e nesse curto espaço de tempo, por si mesmo eternizado. A liberdade do esteta está condicionada apenas aos objetos que Ihe provém satisfação imediata (SULLIVAN, 1978, p. 76). Assim, uma das imagens mais claras que surge ao pensamento a partir dessa descrição do esteta e de sua busca pelo prazer é o paradoxo, pois ele busca o eterno no que é ínfimo e efêmero, e julga encontrar o absoluto naquilo que em pouco tempo o desinteressa de modo mais perene e mais duradouro.

O estádio estético como desenhado por Kierkegaard assume o caráter eminentemente anti-hegeliano por ser antissistemático em sua apresentação imediata (CARLISLE, 2005, p. 53). O momento que concentra a atenção do esteta, o seu perfazimento, a sua aleatoriedade e, principalmente, a sua efemeridade quebram toda a sistemática do Absoluto como proposto por Hegel (1977, p. 147). A sistematicidade hegeliana cai por terra diante dessa descrição do interesse primário do indivíduo, singularizado em tal premissa fundamental de que o momento descreve adequadamente tudo aquilo que é relevante, esteticamente falando. Ainda que o estádio 
em discussão não seja aquele no qual Kierkegaard deposita a sua mais elevada estima, haja vista que seu pensamento ainda se enraizará nos meandros do estádio ético e no estádio religioso, também na forma de conhecimento ético-religioso, o estádio estético já representa um grande dissenso com o hegelianismo.

Assim, há de se deixar afirmado que o mencionado estádio possui a caracterização de ser guiado pelo interesse humano, na mais variada e ampla de suas manifestações, naquilo que ele possa ter de norte mais efêmero em sua delimitação prática, pois é a sua sensibilidade mais comezinha que direciona as ações do homem em tal busca. O direcionamento do indivíduo singular, nesse ponto, não se encontra posto na forma de uma projeção perene ou duradoura de sua existência, de modo que, mesmo que seja um estádio (ou um aspecto de vivência) deveras relevante no pensamento de Kierkegaard, ele é limitado em sua proposta e em seu alcance de continuidade para a vida e para o cotidiano de cada um.

Não obstante, há de se entender que por mais aleatória e efêmera que seja a destinação e a vinculação ao estádio estético, não se pode asseverar, de nenhum modo, que ela esteja atrelada, em maior ou menor extensão, a uma diretriz política. Isso ocorre porque ela é uma variação existencial do interesse humano que não se perfectibiliza de modo idêntico para todos os indivíduos, e nem poderia ser diferente, já que há tantos interesses e tantas variáveis para um mesmo interesse que essa questão não poderia estar centralizada unicamente na questão política.

\subsection{Regramento normativo coletivo e o estádio ético de Kierkegaard}

O outro estádio da vida humana destacado por Kierkegaard é denominado "estádio ético", e ele pode ser resumido, de modo bastante simples, apenas de forma introdutória para a presente explanação, como o estádio da vida humana valorado segundo preceitos de bom e de mau. Assim sendo, em uma breve dissociação do estádio estético, nessa forma 
de apresentação da vida humana são consideradas e julgadas as ações humanas segundo um critério de razoabilidade ancorado na premissa de que determinada ação deve ser compreendida segundo critérios que a qualifiquem como algo bom, ou de forma diametralmente oposta, algo mau. De maneira bastante simples e introdutória ao assunto, o estádio ético pode ser caracterizado como o estádio em que reside a escolha a si mesmo e a adequação do homem à lei e aos valores universais.

A grande problemática na diferenciação não se dará entre o estádio ético e o estádio estético, e, sim, quando for necessário diferenciar o estádio ético do estádio religioso (a ser feito na próxima subseção). Isso se dá porque eles envolvem "conceitos" bastante complexos, sendo que uma mera ou rápida tradução pode ocasionar um mau uso ou uma interpretação equivocada de ambos, algo que tende a gerar incompreensão a respeito de todo pensamento de Kierkegaard. No entanto, esse será um problema a ser enfrentado mais adiante no presente artigo, haja vista que, por ora, a diferenciação operada entre o estádio estético e o ético serve de maneira suficiente para os fins propostos, e para que esse último possa ser mais bem escrutinado a seguir.

Diferentemente do estádio ético, o estádio religioso não é dotado de tantas possibilidades existenciais como aquele outro já definido. Essa é uma decorrência lógica da própria definição de cada um dos estádios mencionados, porque as formas de interesse são amplas e variadas, quase inesgotáveis, ao se pensar que a criatividade humana se aperfeiçoa a cada dia mais, e que está em constante inventividade e evolução. Ao passo que a noção ética do ser humano, que urge em diferenciar as suas ações em boas ou más, enquadra um perfil bem mais restrito de possibilidades existenciais. A definição do que é eticamente relevante, portanto, restringe-se a um leque bem menos amplo de opções e de escolhas para o homem, que deve lidar com tais escolhas e com as suas respectivas consequências.

A noção de consequência é a primeira indicação essencial a ser tratada no estádio ético, pois, diferentemente do mero interesse que caracteriza o estádio estético, é importante denotar que toda a responsabilidade humana 
que é atribuível ao estádio ético deriva do sentimento mais comezinho de consequência. Tal enquadramento ético não é possível no estádio estético, pois, tal como preceitua Kierkegaard (1955, p. 77), o mero interesse não gera uma definição de ele ser algo bom ou mau, intrinsecamente pela própria necessidade de o homem persegui-lo ou deixar de se importar com ele, e isso não pode ser dito sobre o que é usualmente julgado bom ou mal, segundo os critérios eticamente estabelecidos em sociedade. Nesse sentido, por mais que os dois estádios (aliás, os três, pois, como se verá mais adiante, o estádio religioso também pode ser incluído em tal perspectiva) sejam culturalmente relevantes, eles se diferenciam por sua própria atividade e consequências no âmago da sociedade, uma vez que do estádio estético não podem ser derivadas nenhuma das consequências de julgamento ético por ora levantadas (critérios de ser algo bom ou de ser algo mau).

Por mais que a definição de estádios, expressada constantemente nas obras de Kierkegaard, dê uma noção de um circuito ou de uma fase, o próprio autor não nega que haja alguma forma de intersecção entre eles - muito embora, em algumas obras, como o Post-Scriptum bem ressalta (KIERKEGAARD, 2010, p. 134), há uma distância abissal entre o estádio ético e o religioso, por exemplo, necessitando-se de um salto de fé para ultrapassar de um para o outro. É possível sugerir que o estádio estético não é abolido pela ética, sendo por ele incorporado na cotidianidade. Ou seja, o elemento estético permanece de forma relativa no interior de cada escolha historicamente dada no seio da liberdade do indivíduo singular (ALMEIDA; VALLS, 2007, p. 36). A explanação da forma como é fornecida advoga em prol de uma relativização da estética, mas, ainda é capaz de manter uma definição do estádio ético como elemento centralizador da vida do indivíduo singular.

Tomando-se por base que no estádio ético a personalidade está direcionada para si mesma (e reverbera coletivamente a partir da obediência às leis e aos valores universais do círculo cultural em que o homem se insere), o estético (ou os interesses buscados como fim último da predominância estética de cada um) é excluído (como determinante fluído e efêmero da sensibilidade do indivíduo). Relativamente, ele continua a 
subsistir, mas não é mais definitivo no sentido mais próprio e último da existência, embora ainda continue a ter a sua interferência no cotidiano.

Nesse sentido, é importante estabelecer como o estético continua a ser verificado em relação (ou em relativização) ao estádio ético. As escolhas mais simplórias e menos "desinteressadas" naquilo que centra o homem em si mesmo (eticamente) continuam a ser tomadas, mesmo quando um projeto existencialmente relevante é posto em atividade pelo homem. Ou seja, a mais esforçada tentativa de um indivíduo singular em se embrenhar no estádio ético, com todas as suas forças e os seus anseios, não lhe tiram a capacidade, e até a necessidade, de distração, de ter interesses diversos que estarão ao lado do seu projeto mais extenso e mais relevante, existencialmente falando, que é o seu projeto de manutenção de uma vida eticamente escorreita e determinada por tais valores e premissas.

Os modos de diversão e de interesses menos elevados continuarão a existir, em maior ou menor grau, dependendo de como cada um descobre a si mesmo e do modo que traça o seu próprio projeto ético. Contudo, tais elementos estéticos ainda subsistirão, e não serão simplesmente aniquilados pelo estádio ético, como se ele fosse uma lavagem avassaladora de tudo aquilo que não está direta ou intrinsecamente ligado à sua conformação mais própria e mais centrada do que é essencialmente bom (para o indivíduo e para os outros, também). Por mais que o elemento ético seja tido como absoluto na definição desse novo estádio da vida do homem ele não apaga ou zera as experiências esteticamente relevantes do passado, e tampouco obstaculiza de forma a inviabilizar totalmente qualquer manifestação estética de interesse no futuro.

Ao defender o argumento da possibilidade de coexistência entre os dois estádios (ético e estético), André Clair (1976, p. 217) considera que os estádios podem ser compreendidos como etapas individualizadas do transcurso existencial do homem, ou, concomitantemente, podem ser tidas como uma esfera autônoma da existência. De qualquer modo, o estádio possui uma natureza dual em sua disposição existencial. No entanto, não se configura uma dualidade contraditória em si mesmo, e 
sim uma dualidade dialética, que fornece um dinamismo interno entre os dois estádios que correm em paralelo, como, no caso, o estádio estético e o ético, de modo a se adentrar no estádio ético sem carregar, histórica e dialeticamente, os aspectos positivos do estádio estético. A partir do paradoxo que ambas as perspectivas podem pôr em relevo, é possível a sua reunião (sintética) em benefício da subjetividade e daquilo que é construído pelo indivíduo singular igualmente à sua verdade em ambos os estádios postos em paralelo, e não em mero confronto sistemático.

Não é exagero argumentar que o estádio ético dominará as ações e as escolhas do indivíduo em seu melhor direcionamento, de forma global e mais ampla para atingir o seu objetivo mais claro e específico, porém, de modo auxiliar e adjunto a todo esse plexo da conformação ética. $\mathrm{O}$ elemento estético permanece, ainda que de modo menos ativo e relativizado pela própria conjuntura ética que domina o panorama da existência do homem. Assim, ele não se aparta completamente de tudo que é estético ou possa vir a ser, de algum modo, atrelado a tal estádio, apenas os interesses e as inclinações são filtrados e relativizados segundo tais critérios éticos para uma boa vida do homem.

As vicissitudes da vida humana se encontram bem expressas no modo como o estético e o ético prevalecem, lado a lado, ainda que em gradações distintas na vida do homem, mesmo quando ele projeta para si mesmo uma visão ética do mundo. Em algum sentido, todo elemento sensual e a sensibilidade mais própria da vivência estética permanecem, de algum modo, atreladas às ações éticas do indivíduo singular, mesmo sem determiná-las em nenhuma extensão, mas a sua vigência não é tolhida de modo abrupto pelo estádio ético, há uma "coparticipação" do homem nos dois estádios, embora sejam, a princípio, circuitos diversos da vida humana.

O estádio ético, diferentemente do estético, dá uma formação sólida ao indivíduo singular; não se tem uma formação em termos de Absoluto hegeliano, ou seja, o momento pela enfermidade do próprio momento. 0 estádio estético coloca o homem de modo preciso em aspirações precisas, em um ambiente preciso, de maneira que ao tomar consciência de si 
mesmo (de forma mais perene e duradoura, o que não ocorre, no estádio estético, ressalte-se), o homem aceita todas as responsabilidades postas sob sua tutela individual. Ele não se furta ou titubeia a aceitar (ou não) uma responsabilidade, pois sabe que há algo superior (ao mero momento) a ser perdido caso ele não a aceite (KIERKEGAARD, 1955, p. 130). Percebese, por suposto, que há uma solidificação mais elevada da consciência do homem nesse estádio, o respeito às leis e aos costumes e a valoração de bem e de mal se coloca como o estandarte deliberativo do homem, a legislação universal e os usos e costumes institucionalizados são o seu norte normativo, o seu guia ético de procedimento perante a sociedade.

$O$ indivíduo ético possui uma autoconfiança fundamental, uma afirmação de si mesmo perante a legislação vigente que se reverte em uma afirmação da própria autonomia individual (GOUVÊA, 2000, p. 216). Todas as relações estabelecidas a partir do homem ético, e isso inclui até mesmo a sua relação teológica com o divino, são formadas ou conformadas a partir de seus méritos próprios. Arrisca-se a dizer, partindo-se da premissa de uma legislação normativa e de valores universais, que o homem ético é o espeIho do homem eticamente esclarecido em critérios kantianos, um homem conformado pelo imperativo categórico, para quem o dever, e somente o dever, fundamenta a sua autonomia e a sua relação com os demais homens.

O homem ético, portanto, por meio de seus méritos (em dizeres propriamente kantianos, a partir do cumprimento e da obediência à pura formalidade do dever) pressupõe a existência de Deus na universalidade mais abstrata de todas as suas relações, ficando à mercê de tal superficialidade (superada somente no próximo estádio a ser adiante abordado, o estádio religioso). O "deus do homem ético" é sua própria legislação moral, é o regramento que o conduz e o coloca diante de um mundo em que o coletivo e o público devem ser respeitados por estarem escritos em alguma norma de conduta.

A verdade subjetivamente encontrada no estádio ético da vida é aquela que é sempre afirmada pelas leis e pelos costumes. No estádio ético o homem já é capaz de compreender que suas escolhas demandam sacrifícios, 
pois o ato de escolher algo, por si só, é uma renúncia àquilo que não foi escolhido (WEISS, 2008, p. 192). A verdade se estabelece segundo esses critérios, sendo apenas ratificada pelo próprio indivíduo no momento que a aceita, a segue, e, em grande medida a reproduz culturalmente no seio da sociedade em que ele se encontra. A noção teológica contida no estádio ético está bem próxima da noção apresentada por Immanuel Kant (1992, p. 156) no livro A religião nos limites da simples razão, uma vez que a dispersão de Deus como mero ponto invisível e evanescente no plexo de relações culturais, apenas encontra força no seu poder ético, que preenche toda a existência de tal estádio da vida humana (Allison, 2015, p. 61). A noção de Deus, no estádio ético, seguindo as premissas kantiano-hegelianas, é a de um Deus imanentista (JEAN-MARIE, 2008, p. 11), atrelado às tradições culturais, que se encontra no aspecto ético de obediência à lei e aos demais diplomas normativos, dando poder coercitivo aos regramentos sociais estabelecidos.

A crença em Deus, portanto, não está dialeticamente posta na raiz subjetiva da verdade dada em cada indivíduo, ela encontra-se espalhada nos elementos culturais e coletivos da sociedade (BOER, 2013, p. 262), reproduzida em trechos e excertos normativos - por mais laico que o Estado possa ser, ou até mesmo tente ser, tal reprodução simbólica sempre existe, em maior ou menor expressão, a apontar, como exemplo, a prevalência de feriados religiosos em países que se declaram Estados Laicos, como é o caso do Brasil. Assim, Deus assimilado culturalmente, por meio do poder ético da dispersão de tal entendimento, conflui ao imanentismo kantiano outrora aludido. Tal perspectiva, por mais que seja reproduzida subjetivamente em cada homem ético, por mais que ele próprio afirme que tal crença é uma verdade para si mesmo, não brota de uma profunda relação entre ele e o divino, mas, sim, apenas de uma herança cultural, que, em grande parte, pode estar somente sendo reproduzida de modo secularizado, sem nenhuma perspectiva religiosa propriamente dita.

Aliás, é bem provável que tal reprodução da crença em Deus se dê apenas secularmente, haja vista que em uma perspectiva transteísta a noção 
da divindade é essencial no estabelecimento cultural de uma sociedade, mas a sua perpetuação cultural se dá de modo a torná-la despicienda ou pouco atrativa, tornando-se apenas um chamariz propriamente religioso. Por "perspectiva transteísta" (TILLICH, 2014, p. 15) se deve compreender que essa abordagem teológica não está nem vinculada ao ateísmo associado ao panteísmo de Spinoza (2001, p. 58) - posteriormente mais desenvolvido por Hegel (1977, p. 130) -, nem propriamente a uma definição metafísica do cristianismo medieval (escolástico). O transteísmo procura transcender o teísmo tradicional, não sendo nem ateu nem teísta no sentido apresentado. O elemento divino é irrelevante na descrição literal do transteísmo, mas ele pode ser alcançado por cada um, quando há a dedicação a se aperfeiçoar cada vez mais em sua existência (e em sua ligação com o divino). Com base no transteísmo, é possível haver uma apreciação das possibilidades existenciais do homem ao mesmo tempo em que é plausível (ou implausível, dependendo da perspectiva teológica que se adote) expressar uma forma de religiosidade convencional (seja ela o cristianismo ou o judaísmo, a título de exemplo).

Dessa maneira, o transteísmo seria a perspectiva teística mais próxima daquilo que o estádio ético representa como afirmação individual de cada um, em sua autonomia e em sua afirmação de entendimento relacional com Deus e com os demais homens. O mérito de tais relações é sempre individual, pois a ética já estabelece valores e modalidades universais para que se desenvolvam culturalmente, ainda que de maneira meramente simbólica.

\subsection{A diferenciação do estádio religioso e a particularidade teológica do salto de fé como direcionamento ao encontro com Deus}

Os elementos centrais na descrição do estádio ético já foram, por ora, debatidos, de modo que a presente argumentação já se encontra a ponto de adentrar no próximo estádio da vida humana segundo as ponderações de Kierkegaard, o denominado estádio religioso. A subseção em 
desenvolvimento se dedica a abordar, inicialmente, como é que se dá a transição entre os demais estádios (tanto o estético quanto o ético) e o estádio religioso, pois, diferentemente dos demais, é possível que haja uma transição direta de um deles para o religioso, sem que haja uma gradação anterior. Para que isso se torne possível é necessário abordar o que Kierkegaard chama de "salto de fé", o elemento mais aprofundado nesse momento de crise humana, em que a mudança para o estádio religioso se aperfeiçoa. Assim, a presente seção tem como objetivo maior conceituar o estádio religioso da vida humana, e, especificamente, tratar de suas transições e analisar como se opera o "salto de fé".

A "transição" entre o estádio ético e o religioso, ao menos no sentido didático em que todos os estádios estão sendo apresentados, é muito mais complexa e difícil do que qualquer outro tópico levantado até então, como, por exemplo, a mudança entre o estádio estético e o ético. Todas as transições entre os estádios da vida humana são operadas em termos de "crise" (THOMTE, 2009, p. 207). As transições podem ser feitas a partir da angústia ou do desespero, elementos fundamentais na compreensão da dinâmica da vida e de suas mudanças de estágios. Até mesmo por ser uma crise na existência humana mais profunda, a mudança de um estádio mais estável (o ético) para um estádio mais aprofundado e verdadeiro (o estádio religioso) demanda uma análise detida e cuidadosa, para que todas as nuances dessa transição possam ser mais bem explicadas e compreendidas de modo geral.

Um dos pontos complicados em se apresentar a passagem (ou ultrapassagem) entre os dois estádios mencionados reside no aspecto que, diferentemente do estádio estético e ético, não é possível nenhuma congruência entre o estádio ético e o religioso, nem entre o estádio estético e o religioso, muito menos uma tripla configuração em concomitância entre o estético, o ético e o religioso de forma conjunta e sem nenhuma separação factível (BYKHOVSKI, 1976, p. 76). Kierkegaard também não se preocupa em ofertar aos seus leitores uma motivação clara para a mudança entre os estádios (HØFFDING, 1989, p. 121), deixando esse ponto de 
motivação na transição em aberto como uma tarefa para seus intérpretes. Não existe, em um sentido bastante singular e próprio, nenhuma dualidade de ocorrência entre o estádio ético e o religioso, tal como ocorre entre o ético e o estético, como bem explanado em momentos anteriores, para dar conta da vivência cotidiana e entre os dois estádios em relevo.

A dificuldade, portanto, em descrever o estádio religioso, não se encontra (apenas, ressalte-se) em sua própria conceituação (um pormenor que deverá ser analisado mais detidamente na sequência), mas também em sua comparação com o estádio ético e em seu estabelecimento na vida humana como um estádio da existência propriamente independente, e que possui um regramento diverso de todos os outros até então apreciados no estudo em curso. Não há, como em Hegel (1993, p. 44), a partir do desenvolvimento da ideia, elementos-chave para a transição das formas de vida do homem (THULSTRUP, 2014, p. 103). Em Kierkegaard, a transição, apesar de baseada em crises, não se sustenta em momentos centralizados e esquematicamente sistemáticos como na filosofia hegeliana, daí a sua dificuldade de tratamento. O estádio religioso é um apuramento subjetivo muito diferente e mais aprofundado quando comparado com o estádio ético, e ele consegue ter uma "autorreferência" muito mais estável que o voyeurismo estético do outro estádio (MOONEY, p. 2008, p. 42), por exemplo. Assim, sem a centralidade hegeliana e sem elementos que motivem claramente a transição, a descrição desse fenômeno é tarefa bastante complexa de ser apreciada filosoficamente.

Aponte-se que entre o estádio ético e o religioso não existe, propriamente, de forma sequencial ou de ascendência (muito menos em um espiral de epifania, para se usar um termo religioso/ascético mais específico), uma transição entre o estádio ético e o estético, como se houvesse qualquer sorte de evolução social entre ambos os estádios (BERGMAN, 1991, p. 52), em que o indivíduo singular melhora e aperfeiçoa suas capacidades interiores ao ponto de, invariavelmente, evoluir para um estágio mais avançado de convívio social. Há um abismo de vivência e de "conceituação" entre o estádio ético e o religioso que impede uma 
mera evolução temporal entre eles; como se o simples transcurso de uma percepção temporal fosse capaz de aperfeiçoar o homem para a vivência religiosa, algo que, ainda que forçosamente, pode ser indicado entre os estádios estético e ético, mas que para a presente análise não é algo trivialmente forçoso, mas algo totalmente fora dos padrões de entendimento e de estudo da obra de Kierkegaard.

Dada a vacuidade do modo que o esteta conduz a sua vida, pode-se apontar, como alguns estudiosos do tema o fazem (KLEINERT, 2013, p. 103), que o estádio estético pode servir de construção fática da experiência humana a possibilitar a mudança de estádio mais radical e profunda, passando do estético para o religioso. Desse modo, o denominado "salto de fé" (Troens Spring - no original em dinamarquês), um dos constructos kierkegaardianos mais complexos e elementares pode ser descrito como uma passagem direta, do estádio mais primitivo, visceral e sensível, ou seja, do estádio estético em que prevalecem todos os interesses mais pueris e efêmeros do homem, para o estádio religioso, aquele no qual há um grau de elevação e de maturidade subjetiva em um grau deveras superior. Dessa forma, não há qualquer sorte de transição evolutiva, ou de estágios ou etapas sequenciais para o homem atingir o estádio religioso em sua vivência cotidiana.

Do salto de fé, compreende-se que a verdade não está contida na mente do homem, ela está um passo além do nosso ser si-mesmo em relação ao além. Aquilo que se salta é o próprio nada, o universo de possibilidades existenciais do homem. O passo além que é dado, para o estádio religioso, é a realização da relação íntima (subjetiva) com a divindade.

Da caracterização das mudanças de estádios são depreendidos dois aspectos bastante salutares: há uma contraposição fortemente anti-institucional de Kierkegaard, e a salvação humana, tal como pregada por Cristo, que pode ser alcançada por qualquer um, do ladrão ao cobrador de impostos, de modo imediato e sem intermediações (caráter protestante em seu pensamento teológico-filosófico).

O primeiro aspecto, o caráter anti-institucional do pensamento kierkegaardiano, expresso no salto direto do estádio estético para o 
religioso se aperfeiçoa a partir da noção de que não é necessário um prévio regramento institucional-ético por parte de uma conformação eclesiástica, por exemplo, para que o homem atinja o estádio religioso em sua vivência cotidiana. Esse entendimento não supera, de maneira alguma, o aprofundamento subjetivo de cada um a partir da meditação necessária na palavra de Deus aos homens (um dos requisitos necessários para que o caminho até Deus seja percorrido, ainda que de maneira interiorizada no contexto interpretativo-hermenêutico da existência de cada um).

O caráter contrário à institucionalização do pensamento de Kierkegaard não suplanta, de maneira derradeira, a necessidade teológica de o cristão retornar a Deus, seja aprofundando-se nos escritos sagrados, seja na própria comunhão entre os cristãos na sociedade, para que os ensinamentos de Cristo sempre sirvam de exemplo, tanto interiormente quanto de modo coletivo, expressado na subjetividade de cada um. Não basta, portanto, que o cristão conheça a verdade, subjetivamente, ele tem que possuir sua própria verdade, pois sua interioridade se espelha em Deus (PIETY, 2010, p. 198). O cristão não empresta a verdade da igreja, da sociedade ou de seus amigos. Cada um deve encarar sua própria solidão essencial, ver mediante a efemeridade do (estádio) estético, perceber as limitações do (estádio) ético, e emergir como uma pessoa única, sozinha com Deus. Sozinho é que se dá o encontro em face da eternidade, essa é a tarefa heroica (em termos kierkegaardianos) da lida cotidiana (MABRY, 2004, p. 160). O retorno do eterno para o seu congelamento na prática da vivência de cada um é indispensável para que o cristão conviva plenamente segundo os ensinamentos e os moldes de vida do próprio Cristo em si mesmo. A subjetividade do indivíduo singular é espelhada, precipuamente, no estádio religioso, em Cristo.

Assim, não é necessário, no salto de fé operado do estádio estético para o religioso, que haja um "guia" institucionalizado, seja na forma de um Estado que conduz as ações e fomenta comportamentos em cada ser humano, ou que seja na figura clerical, de uma igreja fundamentada em um seguimento único e infalível - Igreja Católica, ou no exemplo mais 
próximo a Kierkegaard, a Igreja Luterana (WATKIN, 1997, p. 34) - que fundamente um preceito ético antes da instauração do estádio religioso na vida de cada homem, o qual é capaz de se aprofundar, subjetivamente, no estádio religioso, sem perfazer tais formalidades institucionais propriamente ditas, tal como descrito e proposto na argumentação em comento.

Semelhantemente, o segundo aspecto a ser denotado é que a salvação do cristão, operada eminentemente a partir do estádio religioso de sua vida, independe de qualquer status prévio, ou de um regramento ético anterior ao momento que ele adentra no próprio estádio em que tal salvação é realizada, ou seja, repise-se no próprio estádio religioso de sua vida. Dessa forma, para que se obtenha a salvação, pouco importa se o estádio precedente do indivíduo singular era a disposição de interesses esteticamente criados na realidade efetiva, ou se era a sua subsunção voluntária e estrita aos regramentos e normativos éticos da sociedade. De maneira sintética, em termos de vida cristã "autêntica" (FORSYTH, 1997, p. 70), pouco importa se anteriormente o homem era um pecador inveterado, um esteta no sentido mais vago e abstrato no sentido de vida efêmero e momentâneo, ou se a sua vida era regrada segundo princípios de moralidade e de ética estritos, ou seja, se o imperativo categórico kantiano era o seu guia do dia a dia de como agir ou proceder diante dos dilemas da vida cotidiana.

O estádio religioso, e as suas disposições, não está condicionado ao passado do homem, ele não é um refém da historicidade particular de cada um. Por causa desse pressuposto não é necessário averiguar se ele era um ladrão, um cobrador de impostos a serviço do Estado ou, até mesmo, se ele era um indivíduo exemplar, seguidor das leis e das determinações coletivas e sociais para um bom desenvolvimento de sua comunidade. Todos os atributos comportamentais anteriormente descritos são plenamente irrelevantes para que o homem logre o salto de fé, e consequentemente, adentre no estádio religioso de sua existência mais autêntica, por assim dizer.

Do que foi exposto, não se pode dizer que a liberdade em Kierkegaard, fundamentada no estádio religioso é, propriamente, anárquica (TANNER, 
1992, p. 155). Todavia, é bastante válido ponderar que ela é, independente da formalização institucional estatal de certa forma em sua conformação social, haja vista ser eminentemente subjetiva, e tal aspecto de interioridade rechaça a prevalência sistemático-estatal reminiscente de Hegel (1977, p. 149), por exemplo. Ao discorrer sobre a interioridade, Kierkegaard (2011, p. 153) fala que "a interioridade é um compreender, mas em concreto o importante é saber como se deve compreender esse compreender". Ainda que o jogo de palavras pareça intrincado, nesse excerto, Kierkegaard critica o intelectualismo do sistema hegeliano ao dizer que a interioridade é um compreender que se dá de modo concreto, e não como algo meramente especulativo. Ademais, mais importante que o resultado da verdade dada subjetivamente na interioridade, é necessário entender "o compreender", ou seja, é de grande valia saber a razão que nela ela se dá subjetivamente na interioridade e não em uma compreensão externa da objetividade.

O estádio ético funciona como um bom espelho normativo da sistemática filosófica hegeliana (tanto quanto do supramencionado viver ético kantiano, aproximando as duas modalidades éticas sem grandes pormenorizações técnicas, dispensáveis para o argumento em relevo), conformando a vida do homem nos regramentos estatais e em suas disposições coletivas. A liberdade do homem, expressa no estádio religioso é empreendida de modo mais aprofundado que em qualquer dos outros estádios, haja vista que a sua relação reflexiva com Deus é muito mais profunda, e seu entendimento de si mesmo, consequentemente, também o é.

Ao retomar a centralidade do argumento contido no estádio religioso da vida humana é necessário discorrer um pouco acerca do já mencionado, mas não aprofundado ainda, "salto de fé", pois é esse momentum da vida do homem que se faz a transição entre os estádios (seja ele o estético ou o ético) para a imersão na vida religiosa, o ápice da vida do homem (cristão). Antes de adentrar propriamente na discussão e no empreendimento do salto de fé e as suas repercussões no estádio religioso, é de grande importância destacar que o ideal de vida cristão, e o próprio 
cristianismo, em uma visão mais ampla do assunto, não são apenas mais um dos tópicos relevantes para o estudo empreendido por Kierkegaard.

Dessa maneira, o tornar-se cristão, que é na mesma medida existencial um tornar a si mesmo (cristão), é uma temática que perpassa todo o pensamento kierkegaardiano, não sendo simplesmente mais um tópico relevante para ele (ROOS, 2014, p. 360). A libertação do desespero consiste em ser si mesmo, um transcurso que liberta o homem e se efetiva na síntese absoluta no estádio religioso, momento de liberdade mais aprofundada para o homem em si mesmo. Dada a importância desse percurso, e de toda essencialidade disposta no tornar-se cristão dentro da filosofia de Kierkegaard, a liberdade só é oferecida segundo tais premissas e critérios, àquele que conseguiu dar o salto de fé e adentrar, perenemente, no estádio religioso da vida humana.

Não se tornar si mesmo, e, consequentemente, perder a si mesmo, é uma das coisas mais perigosas ao homem, como destaca novamente Jonas Roos (2014, p. 361), uma vez que a fuga dessa realização faz com que a existência do homem seja vazia nos dois outros estádios possíveis. A saber, o tolhimento do ser si mesmo, jogando o homem no desespero prevalente, possui uma dupla repercussão, uma no estádio estético, operada pela própria efemeridade de seus interesses e de seus apegos transitórios e instáveis, e outra no estádio ético, repercussão que é provocada (ou simplesmente acarretada, por assim dizer) em função da vacuidade do regramento normativo da coletividade, que não dá azo ao desenvolvimento da interioridade do homem e tampouco fornece os elementos mais caros à formação de sua verdade a partir da subjetividade; o tolhimento é a marca impressa pela normatividade operante sobre o homem. A princípio, pode-se pensar que só há tolhimento normativo no estádio ético, aquele em que o homem toma consciência da necessidade de seguir regras socialmente postas. Todavia, é importante denotar mais uma vez que o estádio estético não se desvencilha completamente do estádio ético, de modo que todo o regramento social, ainda que tenha uma repercussão menor no estádio estético, pode ocasionar-lhe "danos" ou "alterações" no status de seus interesses. Um dos exemplos que pode ser dado de tolhimento normativo no estádio 
estético é quando alguma lei ou norma proíbe ou suprime determinada atividade, inviabilizando-a totalmente na prática. Ainda que a diretriz seja posta para o estádio ético (em que o homem tem que obedecer a lei), sem que o interesse deixe de ser factível na prática, ele, consequentemente, também desaparece do estádio estético, pois deixa, indiretamente, de ser uma opção para o homem de satisfazer seu interesse.

A síntese operada no estádio religioso é a do infinito (em Deus) com o finito do horizonte existencial do homem, da temporalidade de suas escolhas e do atemporal do descanso eterno em Jesus Cristo, o escopo primordial de toda a existência cristã. O salto de fé, não é, portanto, apenas um salto para a fé, é um salto para a síntese do homem religioso, é a conformação desse estádio em tais (aparentes) paradoxos da vida humana, rica e complexa em todos os seus aspectos existenciais.

O salto de fé é uma habilidade que trespassa o homem do estádio em que ele se encontra (qualquer que seja esse estágio) para o estádio religioso, de modo que o capacita a agir de modo a não ter nenhum arrependimento em deixar de lado a razão comum. A imagem do salto da fé, emblematicamente descrita no Post-Scriptum, é a do salto sobre 70 mil braças de água de profundidade. Assim, o salto de fé é um salto em direção ao abismo, e, para que isso ocorra, não basta simplesmente o ato de "saltar", afinal, ele é o resultado de um processo da própria fé, haja vista que o passo anterior ao salto é o que consolida a própria fé do homem em Deus (BACKHOUSE, 2011, p 114). O abismo criado por Kierkegaard ao descrever o salto de fé, semelhantemente, pode ser compreendido como uma expressão do nada. Saltar sobre o nada que engloba as possibilidades do homem, pois, até tal momento, apenas há a fé para sustentar a força e a vontade do próprio salto. O salto de fé é um lançar-se para o nada, tal qual sem nada esperar em retribuição, o nada é o pano de fundo para que todas as possibilidades existenciais do homem venham a se tornar alguma coisa, ou que, de outra maneira, simplesmente o abismo seja encontrado.

Entretanto, semelhantemente à narrativa de Abraão, em Temor e Tremor, Kierkegaard (2012, p. 81) fala do cavaleiro da fé, e que o homem 
que dá o salto de fé para o estádio religioso tem fé de que retornará, pois o amor total de Deus reverte ao próprio homem. Abraão tinha fé (expressa de um modo inabalável e plenamente transcendente à ética e a moralidade comum) de que retornaria do monte Moriah com seu filho único, Isaac, pois foi isso que ele avisou aos seus empregados quando estava a se dirigir para efetuar um sacrifício mesmo sem estar a carregar nenhum objeto de imolação (um cordeiro, por exemplo, já que seu filho seria imolado, suspendendo ele toda a ética coletiva para seguir os desígnios de Deus).

A suspensão da ética com a imersão no estádio religioso pleno é dada pela decisão própria de Abraão em seguir os desígnios de Deus, o salto da fé se opera no momento que ele chega ao clímax da narrativa ao preparar toda a situação para imolar seu primogênito, e a recompensa de sua fé. Ao operar a plena descontinuidade entre o estádio ético e o religioso, Abraão encontra seu descanso no estádio religioso em que a bonança é a continuidade de sua vida e a extensão da sua semente em uma grande nação, tal qual prometido a ele anos antes por Deus (SCHRAG, 1994, p. 27). O cumprimento da promessa é a síntese da felicidade no estádio religioso no exemplo de Abraão. A superação da ética é um dos meios necessários e indisponíveis para que o elemento religioso de comunhão plena com Deus seja alcançado, subjetivamente, entre Abraão e o divino. Nesse sentido, por mais que se possa argumentar contrariamente que essa é apenas uma narrativa mítica, que o Deus da Bíblia apenas representa uma noção valorativa de obediência, negar a crença de Kierkegaard de que o estádio religioso suplanta a normatividade (provida pelo estádio ético) acaba por configurar uma negação frontal e plena de todo o seu pensamento. Negar essa premissa básica de que o estádio religioso exige sacrifícios práticos em prol do aprofundamento subjetivo com Deus consiste em aniquilar todos os estádios pensados por Kierkegaard e negar qualquer relação subjetiva com Deus. Sem o estádio religioso não há verdade na subjetividade do homem, logo, nenhuma verdade é possível, seja ela dada subjetiva ou objetivamente para o homem. 
De modo semelhante, há de dizer que o salto de fé implica, de modo derradeiro, como a própria raiz conceitual do termo vem a sugerir, fé no retorno, e a superação do abismo do nada, um salto para ser aquilo que ele se tornará a ser si mesmo (DE GRUCHY, 2001, p. 82). Por mais redundante que a última sentença possa parecer, o tornar-se si mesmo é o objetivo mais claro e cristalino do salto da fé após a sua realização. Salta-se para o nada com a convicção de que Deus é o caminho, e com a certeza da própria vitória em Cristo. Esse movimento de síntese, do eterno com o finito, das possibilidades existenciais contraindo-se e se expandindo mutuamente em torno da fé é a caracterização inicial do estádio religioso, e de (alguns) seus paradoxos mais elementares.

\section{Considerações finais}

A apresentação dos três estádios estéticos dá um panorama geral do entendimento acerca da existência para Kierkegaard. Com a análise operada nesse capítulo é possível compreender como a assertiva da verdade como subjetividade se molda à filosofia dos dois autores mencionados, e como ela assume um caráter transteístico a partir de então, sendo repetida como o norteamento filosófico do século $X X$.

Em termos conclusivos, há de se levar em conta a aceitação do entendimento que os diversos estádios da vida são comutáveis, isto é, eles podem ser prevalentes de modo concomitante sem que haja uma necessária prevalência entre eles. No entanto, há de se destacar que mesmo não havendo a mencionada prevalência, o estádio religioso possui um status ontoteológico diferenciado. Em virtude do salto de fé, o mencionado estágio religioso possui uma diferença em sua aproximação teológica, com a realidade última da apreciação e da experimentação do divino, sem que os demais estágios (estádios) sofram qualquer sorte de demérito em função de tal ocorrência.

Há de se deixar assentado, e isso, certamente, consiste no maior avanço interpretativo que é possível de ser dado diante da contextualização 
filosófica apresentada, que a vida a ser vivida no estágio religioso não é algo obtuso, inatingível ou etéreo. A transição a ser efetuada, ainda que não necessária, é preferível a todo aquele que almeje uma imersão derradeiramente "autêntica" em sua existência. Se a mesmice da lida cotidiana é suficiente para lhe preencher os espaços contidos nos demais estágios, certamente que não haverá o avanço para o salto de fé, aliás, ele não será efetuado, nem sequer será cogitado, já que para que se possa minimamente vislumbrar tal situação existencialmente profunda, exige-se que a angústia já tenha se instalado como motor do pensamento sobre a própria existência, sem esse pressuposto o salto de fé nem sequer é cogitado, quiçá efetuado.

Todavia, há de se destacar que ao se adentrar no salto sobre o abismo, o abismo das 70.000 braças, ou seja, uma fossa abissal que existe entre os demais estágios e o estágio religioso, o homem adentra em uma nova perspectiva existencial, algo impensável preteritamente, e que não pode ser retrocedido uma vez em comunhão com Deus; segundo o modelo de Cristo, inexiste outra possibilidade teológica ou existencial para quem saltou para a fé. O ápice da paixão humana, de sua vivência e sua existência estão completos, qualquer outro estágio ou situação mais sublime que essa, somente podem ser encontradas na comunhão puramente espiritual descrita na Bíblia após a morte, mas, como se trata de algo além dos limites da pura e simples existência, escapa aos desígnios do estágio religioso, que se efetua e se exprime ainda em vida, sem que se projete (ao menos necessariamente) uma profusão sobrenatural para o depois.

Dessa maneira, há de se concluir, derradeiramente, que há uma pluralidade enorme de formas e maneiras de se viver a própria vida. Ela pode ser desmesuradamente estética ao ponto de se fechar sobre a redoma dos interesses, ao ponto do homem se tornar escravo de seus desejos diante da multiplicidade dos interesses; ela pode ser vivida segundo regramentos éticos-normativos estritos, sem desvios ou contradições de maior complexidade; mas, de outra banda, pode ser uma pura negação ética, um estorvo deletério da normatividade. Todas essas são possibilidades de uma vida a ser vivida, não se trata, ao destrinchar conceitualmente os estádios, que 
Kierkegaard não se ocupe em tecer julgamentos, ainda que seja didático o suficiente para encaminhar quais as alternativas mais indicadas para o cristão. Assim, trilhando o caminho modelar do cristão que é justamente o de Cristo, o encaminhamento máximo, o ápice desse percurso, é o salto de fé, o momento imediatamente anterior a se adentrar no estádio religioso. Ao atingir tal estádio, o cristão se firma e se estabelece plenamente nessa qualidade de passionalidade cristã, uma via sem retorno. Nos demais estádios, o homem pode até ter interesses cristãos, pode até seguir uma normatividade "pós-mosaica" cristã, mas jamais será considerado religiosamente um cristão, status somente alcançável após o supramencionado salto de fé.

Assim, é possível se vislumbrar transições entre os mencionados estágios e até mesmo uma confluência existencial entre eles, afinal, em última instância, todos estão interconectados com a existência humana, e não são dela desligados em nenhuma circunstância. Essa conexão fundamental é que dá azo a Kierkegaard pensar uma possibilidade de superação da filosofia (hegeliana) por meio do cristianismo. Libertandose das amarras da sistematicidade e da especulação, é possível se pensar a vida diante do interesse, da normatividade e da experiência religiosa, sem ser necessário pagar tributos intelectuais a uma forma sistemática de pensamento atrelada necessariamente a conceitos que engessa filosoficamente a vida do homem.

\section{Referências}

ALLISON, Henry E. Kant's Transcendental Deduction: An Analytical-Historical Commentary. Oxford: Oxford UP, 2015.

ALMEIDA, J. M.; VALLS, A. Kierkegaard. Rio de Janeiro: Jorge Zahar Editor, 2007.

BACKHOUSE, S. Kierkegaard's critique of christian nationalism. Oxford: Oxford UP, 2011.

BERGMAN, S. H. Dialogical philosophy from Kierkegaard to Buber. Albany: SUNY Press, 1991. 
BOER, Roland. In the Vale of Tears: On Marxism and Theology. Leiden: Koninklijke Brill, 2013.

BYKHOVSKI, Bernard. Kierkegaard. Tradução: Henry F. Mins. Amsterdam: B. R. Grüner, 1976.

CARLISLE, Clare. Kierkegaard's Philosophy of Becoming: Movements and Positions. Albany: SUNY Press, 2005.

CLAIR, André. Pseudonyme et Paradoxe: La Pensée Dialectique de Kierkegaard. Paris: Librairie Philosophique J. Vrin, 1976. https://doi.org/10.1017/ $\underline{\text { so012217300017431 }}$

DE GRUCHY, J. W. Christianity, art, and transformation: theological aesthetics in the struggle for justice. Cambridge: Cambridge UP, 2001.

ERIKSEN, N. N. Kierkegaard's category of repetition: a reconstruction. Berlin: Walter de Gruyter, 2000.

FARAGO, F. Compreender Kierkegaard. Tradução: Ephraim F. Alves. Petrópolis: Vozes, 2006.

FORSYTH, J. Faith and human transformation: a dialogue between psychology and theology. Oxford: University Press of America, 1997.

GOUVÊA, Ricardo Quadros. Paixão pelo Paradoxo. São Paulo: Novo Século, 2000.

HEGEL, G. W. F. Ciencia de la logica. 6. ed. Traducción: Augusta e Rodolfo Modolfo. Buenos Aires: Librarie Hachette, 1993.

HEGEL, G. W. F. Phenomenology of spirit. Translation: A. V. Miller. Oxford: Oxford UP, 1977.

HØFFDING, Harald. Søren Kierkegaard som Filosof. Farum: Danske forlag, 1989. JEAN-MARIE, Vivaldi. Kierkegaard: History and Eternal Happiness. Lanham, MD: University Press of America, 2008.

KANGAS, D. J. Kierkegaard's instant: on beginnings. Bloomington: Indiana UP, 2007.

KANT, Immanuel. A Religião nos Limites da Simples Razão. Tradução: Artur Morão. Lisboa: Edições 70, 1992.

KIERKEGAARD, S. O conceito de angústia: uma simples reflexão psicológico-demonstrativa direcionada ao problema dogmático do pecado hereditário de Vigilius Haufniensis. Tradução: Álvaro Valls. Petrópolis: Vozes, 2011. 
KIERKEGAARD, S. Estética y ética: en la formación de la personalidad. Traducción: Armand Marot. Buenos Aires: Nova, 1955.

KIERKEGAARD, S. Migalhas filosóficas: ou um bocadinho de filosofia de João Clímacus. Tradução: Álvaro Valls. Petrópolis: Vozes, 1995.

KIERKEGAARD, S. Post Scriptum: no científico y definitivo a "migajas filosóficas". Traducción: Javier Teira e Nekane Legarreta. Salamanca: Ediciones Sígueme, 2010.

KIERKEGAARD, S. The sickness unto death: a christian psychological exposition for upbuilding and awakening. 29. ed. Princeton: Princeton UP, 1980. https://doi.org/10.1515/9781400847198-024

KLEINERT, M. Theodor Häcker: the mobilization of a total author. In: STEWART, J. B. (org.). Kierkegaard's influence on literature, criticism, and art: the germanophone world. Burlington, $\mathrm{NH}$ : Ashgate, 2013. p. 91-114.

KNAPPE, U. Theory and practice in Kant and Kierkegaard. Berlin: Walter de Gruyter, 2004.

LIEHU, Heidi. Søren Kierkegaard's Theory of Stages and its Relation to Hegel. Helsinki: Philosophical Society of Finland, 1990.

MABRY, J. R. Heretics, mystics \& misfits. Berkeley: Apocryphile, 2004.

McDONALD, W. Kierkegaard's demonic boredom. In: DALLE PEZZE, B.; SALZANI, C. (org.). Essays on Boredom and Modernity. Amsterdam: Rodopi, 2009. p. 61-84. https://doi.org/10.1163/9789042032125_004

MIDDLETON, T. Modernism: critical Concepts in literary and cultural studies. London: Routledge, 2003. v. 3.

MOONEY, E. F. Postscripts ethics: putting personality on stage. In: MOONEY, E. F. (org.). Ethics, love, and faith in Kierkegaard: philosophical engagements. Bloomington: Indiana UP, 2008. p. 39-55. https://doi.org/10.1111/j. 1468-0025.2010.01645.X

NYGREN, E. H. Existentialism: Kierkegaard. In: GEISLER, N. L. (org.). Biblical errancy: an analysis of Its philosophical roots. Grand Rapids: Zondervan Pub. House, 1981. p. 105-132.

PIERCEY, R. The uses of the past from Heidegger to Rorty: doing philosophy historically. Cambridge: Cambridge UP, 2009. https://doi.org/10.1017/ cbo9780511576256.002 
PIETY, M. G. The Epistemology of the Postscript. In: FURTAK, R. A. (org.). Kierkegaard's concluding unscientific postscript: a critical guide. Cambridge: Cambridge UP, 2010. p. 190-203. https://doi.org/10.1017/cb09780511782008.011 PODMORE, S. D. Kierkegaard and the self before god anatomy of the abyss. Bloomington: Indiana UP, 2011.

ROOS, J. Religião, Temporalidade e corporeidade em Kierkegaard. Numen, Juiz de Fora, v. 17, n. 1, p. 347-364, 2014.

RUDD, Anthony. Kierkegaard and the Limits of the Ethical. Oxford: Oxford UP, 1997.

SCHRAG, C. O. Philosophical papers betwixt and between. Albany: SUNY Press, 1994.

SPINOZA, Benedictus. Ethics: Demonstrated in Geometrical Order. Translation: W. H. White, A. K. Stirling. Hertfordshire: Woodsworth, 2001.

SULLIVAN, F. Russell. Faith and Reason in Kierkegaard. Washington, D.C.: University Press of America, 1978.

TANNER, J. S. Anxiety in Eden: A kierkegaardian reading of Paradise Lost. Oxford: Oxford UP, 1992.

THOMTE, Reidar. Kierkegaard's Philosophy of Religion. Eugene, OR: Wipf e Stock, 2009.

THULSTRUP, N. Kierkegaard's relation to Hegel. Translation: George L. Stengren. Princeton: Princeton UP, 2014.

TILLICH, Paul. The Courage to Be. New Haven: Yale UP, 2014.

WATKIN, J. Kierkegaard. London: Continuum, 1997.

WEISS, Gail. Refiguring the Ordinary. Bloomington: Indiana UP, 2008. 